\title{
ROCK2 and MYLK variants and high-altitude pulmonary edema
}

\author{
This article was published in the following Dove Press journal: \\ The Application of Clinical Genetics \\ 2 August 2016 \\ Number of times this article has been viewed
}

\author{
Gaurav Sikri \\ Srinivasa Bhattachar \\ Department of Physiology, Armed \\ Forces Medical College, Pune, \\ Maharashtra, India
}

Correspondence: Gaurav Sikri Department of Physiology, Armed Forces Medical College, Sholapur Road, Pune, Maharashtra 4I I040, India

Email drgaurav35@gmail.com

\section{Dear editor}

We have read the article titled "ROCK2 and MYLK variants under hypobaric hypoxic environment of high altitude associate with high altitude pulmonary edema and adaptation" by Pandey et $\mathrm{al}^{1}$ with profound interest. The authors have reported an association of rho-associated coiled-coil kinase isoform 2 (ROCK2) and myosin light chain kinase (MYLK) with high-altitude pulmonary edema (HAPE) in the Indian population. As per the Lake Louise Consensus on the definition and quantification of altitude illness, HAPE is diagnosed by presence of at least two of the symptoms such as dyspnea at rest, cough, weakness or decreased exercise performance, chest tightness, or congestion; and at least two of the signs such as rales or wheezing in at least one lung field, central cyanosis, tachypnea, and tachycardia, in the background of recent gain of altitude. ${ }^{2}$ The authors have used a detailed medical examination for these subjects and have recorded the mandatory clinical findings for HAPE. They have described findings of mean arterial pressure and peripheral capillary oxygen saturation but have inadvertently not reported the resting heart rate and respiratory rate of their subjects. The reporting of these clinical parameters (especially tachypnea and tachycardia) would have fulfilled all the criteria required for the diagnosis of HAPE. The authors have also mentioned that an exhaustive questionnaire was used for the diagnosis of HAPE. As physiologists with interest in the field of high-altitude (HA) medicine, we are interested in knowing the details of this questionnaire.

The authors of this study have also ruled out the presence of acute mountain sickness (AMS) by using the Lake Louise Questionnaire only in HAPE control subjects but not in HAPE-susceptible ones, which is not understandable as AMS and HAPE are two distinct HA-related acute illnesses occurring because of the involvement of two different physiological systems, the central nervous system and the pulmonary system, respectively. ${ }^{3}$ If uniformity of ascent and rest (or exercise) after entry is assumed, the likelihood of occurrence of AMS in both controls and HAPE-susceptible subjects remains the same. ${ }^{4}$

The authors have concluded by reporting a role of ROCK 2 and MYLK in determining the susceptibility of an individual to HAPE, but practical application of this outcome in the field of HA medicine remains obscure. HAPE is a rare disease, as acknowledged by the authors, and has an incidence of only $0.31 \%$ among Indian 
male lowlanders after an acute ascent (by air) to an altitude of $3,400 \mathrm{~m}$ in the Western Himalayas. ${ }^{5}$

\section{Disclosure}

The authors report no conflicts of interest in this communication.

\section{References}

1. Pandey P, Mohammad G, Singh Y, Qadar Pasha MA. ROCK2 and MYLK variants under hypobaric hypoxic environment of high altitude associate with high altitude pulmonary edema and adaptation. Appl Clin Genet. 2015;8:257-267.
2. Roach RC, Bartsch P, Hackett PH, et al. The Lake Louise consensus on the definition and quantification of altitude illness. In: Sutton JR, Coates G, editors. Hypoxia and Molecularmedicine. Burlington, VT: Queen City Press; 1993:327-330.

3. Luks AM. Physiology in medicine: a physiologic approach to prevention and treatment of acute high-altitude illnesses. J Appl Physiol (1985). 2015; 118:509-519.

4. Luks AM, McIntosh SE, Grissom CK, et al. Wilderness medical society practice guidelines for the prevention and treatment of acute altitude illness: 2014 update. Wilderness Environ Med. 2014;25:S4-S14.

5. Apte CV, Tomar RKS, Sharma D. Incidence of high altitude pulmonary edema in low-landers during re-exposure to high altitude after a sojourn in the plains. Med J Armed Forces India. 2015;71:214-220. 


\section{Authors' response}

Priyanka Pandey 1,2

Yogendra Singh ${ }^{1,2}$

Ghulam Mohammad ${ }^{3}$

MA Qadar Pasha ${ }^{1,2}$

'Functional Genomics Unit, CSIR-Institute of Genomics and Integrative Biology, Delhi, ${ }^{2}$ Department of Biotechnology, University of Pune, Ganeshkhind, Pune, Maharashtra, ${ }^{3}$ Department of Medicine, SNSNM Hospital, Leh, Ladakh, Jammu and Kashmir, India

Correspondence: MA Qadar Pasha

CSIR -Institute of Genomics and Integrative Biology, Mall Road,

Delhi II 0 007, India

Email qpasha@igib.res.in

\section{Dear editor}

We appreciate the authors Gaurav Sikri and Srinivasa Bhattachar for their judicious comments on our manuscript entitled "ROCK2 and MYLK variants under hypobaric hypoxic environment of high altitude associate with high altitude pulmonary edema and adaptation." We also express our gratitude to the Editor-in-Chief, The Application of Clinical Genetics, and the staff at Dove Medical Press for their kind support toward the publication of our manuscript.

In the letter, Sikri and Bhattachar have asked for the details of the questionnaire administered while recruiting the subjects in the study. We would like to state that the questionnaire consisted of two parts. The information was filled in by trained medical staff (physicians).

In the first part, we have the following headings under which information was filled: age, sex, altitude of birth (birth place), weight, height, arterial oxygen saturation, ethinicity (religion/caste), blood group, hemoglobin, blood sugar, serum cholesterol, body temperature, blood pressure, respiratory rate, pulse per minute, medications (if any), previous history of acute mountain sickness (AMS), high-altitude pulmonary edema (HAPE) status, high-altitude cerebral edema status, alcohol intake, smoker or nonsmoker status, and finally, whether the subjects or any of their immediate relatives had ever visited an altitude of $>3,500 \mathrm{~m}$ or not; if yes, then how many times and had anyone ever suffered with any kind of altitude-related disease. In the second part, we had a questionnaire similar to the "Lake Louise AMS Questionnaire" (http://www.high-altitude- medicine.com/ AMS-worksheet.html).

We appreciate the comment by the authors wherein they have queried regarding the ruling out of AMS in HAPEsusceptible individuals. We would like to state here that Lake Louise scoring was applied to rule out any symptoms of AMS among both HAPE patients and HAPE controls as is evident from the questionnaire details mentioned herein Of note, we would like to state here that HAPE-p were the individuals who had developed HAPE upon their first visit to the high-altitude region. We are grateful to get an opportunity to clarify this information in this short reply.

In the letter, the authors have also asked about the pulse rate of the subjects. We would like to state that the pulse rates for HAPE patients, HAPE controls, and highlanders were $\sim 92$ beats per minute (bpm), $\sim 80 \mathrm{bpm}$, and $\sim 84 \mathrm{bpm}$, respectively. In our manuscript, we had tried to bring out all the details about the HAPE patients and healthy controls. We had also tried to put in all the information related to the clinical parameters relevant to the study. We admit that there could be some information pertaining to the subjects that has not been mentioned in the manuscript. But it was not viable to describe each and every minute particular.

\section{Disclosure}

The authors report no conflicts of interest in this communication.

Dove Medical Press encourages responsible, free and frank academic debate. The content of the The Application of Clinical Genetics 'letters to the editor' section does not necessarily represent the views of Dove Medical Press, its officers, agents, employees, related entities or the The Application of Clinical Genetics editors. While all reasonable steps have been taken to confirm the content of each letter, Dove Medical Press accepts no liability in respect of the content of any letter, nor is it responsible for the content and accuracy of any letter to the editor.

\section{Publish your work in this journal}

The Application of Clinical Genetics is an international, peer-reviewed open access journal that welcomes laboratory and clinical findings in the field of human genetics. Specific topics include: Population genetics; Functional genetics; Natural history of genetic disease; Management of genetic disease; Mechanisms of genetic disease; Counselling and ethical issues; Animal models; Pharmacogenetics; Prenatal diagnosis; Dysmorphology. The manuscript management system is completely online and includes a very quick and fair peer-review system, which is all easy to use. Visit http://www.dovepress.com/testimonials.php to read real quotes from published authors. 